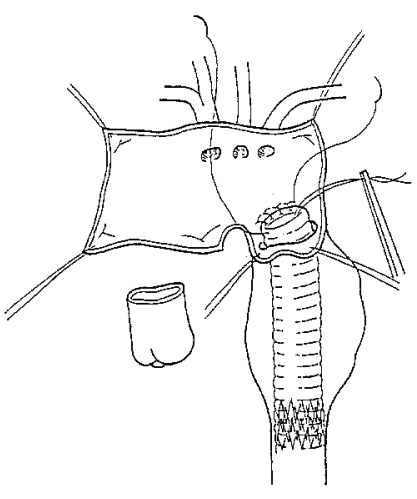

A

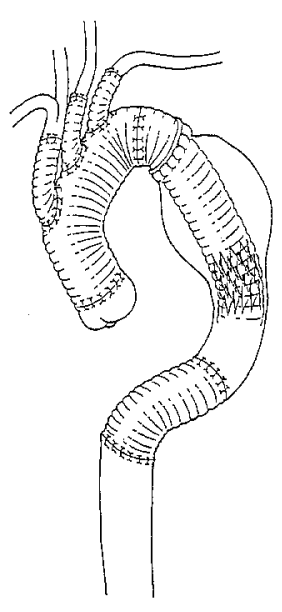

B
Fig. 1. Schematic drawing of operation. See text for details.

in which the dead space around the long elephant trunk was filled with clot and further operation was not needed. ${ }^{2}$ The authors highlighted this phenomenon as a further potential use of this technique. Crawford and associates ${ }^{3}$ reported complications of this method: kinking and occlusion of the graft, paraplegia as a result of clot around the graft, and peripheral thromboembolism caused by flapping action. They stated that these complications were more likely when the trunk was longer.

To avoid these potential complications of a long elephant trunk graft, we used a stent at the distal end to fix the graft to the native aortic wall. By this method, we could prevent any kinking and flapping action of the graft. In addition, we can expect complete obliteration of the dead space around the graft even if there are patent intercostal arteries, because the hemodynamic conditions

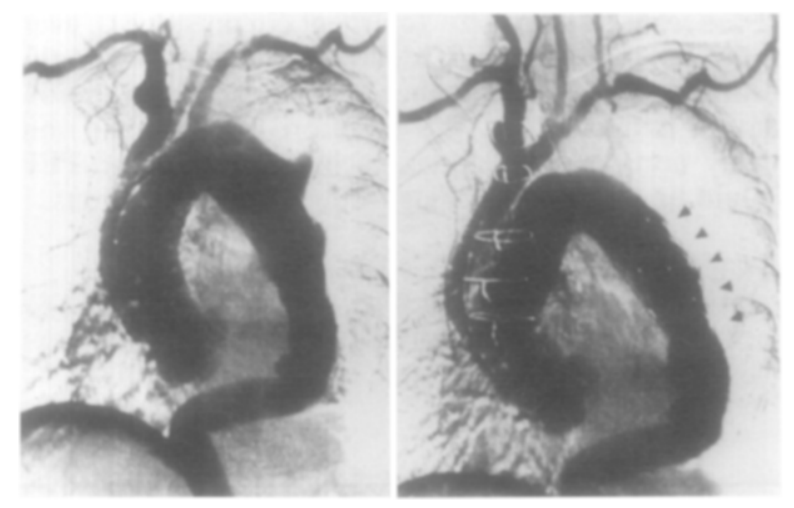

Fig. 2. Angiograms before (left) and after (right) operation. Arrowheads indicate the location of the stent.

around the graft are similar to those after thromboexclusion. Although there may be a limitation on indications for our method, it is a useful alternative for patients at poor risk and those with pulmonary disease.

\section{REFERENCES}

1. Borst HG, Walterbusch G, Schaps D. Extensive aortic replacement using "elephant trunk" prosthesis. Thorac Cardiovasc Surg 1983;31:37-40.

2. Borst HG, Frank G, Schapes D Treatment of extensive aortic aneurysm by a new multiple-stage approach. J Thorac Cardiovasc Surg 1988;95:11-3.

3. Crawford ES, Coselli JS, Svensson LG, Safi HJ, Hess KR. Diffuse anieurysmal disease (chronic aortic dissection, Marfan, and mega aorta syndromes) and multiple aneurysm: treatment by subtotal and total aortic replacement emphasizing the elephant trunk operation. Ann Surg 1990;211:521-37.

4. Heinemann MK, Buehner B, Jurmann MJ, Borst HG. Use of the "elephant trunk technique" in aortic surgery. Ann Thorac Surg 1995;60:2-7.

\title{
CARDIOPULMONARY BYPASS FOR HEPARIN-INDUCED THROMBOCYTOPENIA: MANAGEMENT WITH A HEPARIN-BONDED CIRCUIT AND ENOXAPARIN
}

\author{
Anoop K. Ganjoo, MCh, DNB, Michael G. Harloff, CCP, and W. Dudley Johnson, MD, Milwaukee, Wis.
}

Heparin-induced thrombocytopenia (HIT) is a potentially dangerous condition in patients needing cardiac operation because the use of unfractionated, standard

From St. Mary's Hospital, Milwaukee, Wis.

Received for publication March 19, 1996; accepted for publication April 15, 1996.

Address for reprints: W. Dudley Johnson, MD, 3300 South 16th St., Milwaukee, WI 53215.

J Thorac Cardiovasc Surg 1996;112:1390-2 heparin for cardiopulmonary bypass (CPB) can cause severe bleeding, thromboembolism, and even death. Several strategies that avoid or modify the use of standard heparin have been tried in such situations but none has gained universal acceptance. We describe here the successful use of a heparin-bonded CPB circuit and enoxapa-

Copyright (C) 1996 by Mosby-Year Book, Inc. $0022-5223 / 96 \$ 5.00+0 \quad \mathbf{1 2 / 5 4 / 7 4 1 8 2}$ 
rin, a low molecular weight heparin (LMWH), in a patient with HIT undergoing coronary artery bypass grafting.

Case report. A 70-year-old man with severe triple-vessel disease, unstable angina, and severe congestive heart failure was referred to us for coronary artery bypass grafting. At the previous hospital, HIT was suspected when the platelet count dropped from $313 \times 10^{9} / \mathrm{L}$ to $77 \times 10^{9} / \mathrm{L}$ after 6 days of heparin therapy and confirmed with positive platelet aggregation studies with standard heparin. Heparin administration was stopped immediately and the patient was given therapy with the LMWH enoxaparin (Lovenox, RhonePoulenc Rorer Pharmaceuticals, Collegeville, Pa.) $30 \mathrm{mg}$ every 12 hours, although separate aggregation tests were not done with this drug. The platelet count at hospital admission was $68 \times 10^{9} / \mathrm{L}$ and varied from $92 \times 10^{9} / \mathrm{L}$ to $172 \times 10^{9} / \mathrm{L}$ over the next 4 days. Other coagulation parameters were within normal limits.

CPB was planned with a circuit coated with Carmeda Bioactive Surface (Medtronic, Anaheim, Calif.). The circuit included a Bio-Medicus vortex pump, a Maxima Plus membrane oxygenator, an MVR 1600 venous reservoir bag, an arterial line filter, and a cardiotomy reservoir, all manufactured by Medtronic; two $32 \mathrm{~F}$ caval cannulas and an 8.0 aortic cannula (Sarns Inc., Ann Arbor, Mich.) and a $14 \mathrm{~F}$ Argyle aortic root vent (Sherwood Medical, St. Louis, Mo.). For added anticoagulation intraoperatively, enoxaparin administration was continued using the manufacturer's recommended protocol. Twenty milligrams of enoxaparin was added to the prime, a further $80 \mathrm{mg} / \mathrm{m}^{2}$ was given after sternotomy, and an infusion was maintained at a rate of $40 \mathrm{mg} / \mathrm{m}^{2}$ per hour once CPB was instituted. Flow rates varied from 2 to $5 \mathrm{~L} / \mathrm{min}$, and intermittent ischemic fibrillatory arrest with mild hypothermia to $34^{\circ} \mathrm{C}$ was used. Activated clotting time was determined every 30 minutes with a Hemostasis Management Systems device (Medtronic) and ranged from 236 to 321 seconds. After about 4 hours of CPB, 130 minutes of total ischemic time, and completion of six vein grafts, the patient was removed from bypass with intraaortic balloon pump support.

For reversal of heparin, $500 \mathrm{mg}$ of protamine sulphate was given. No evidence of visible thrombus, debris, or fibrin strands was found on close examination of the bypass circuit. The platelet counts remained higher than $98 \times 10^{9} / \mathrm{L}$ throughout the operation. In the first 24 hours after operation, the patient lost $1.45 \mathrm{~L}$ of fluid, for which transfusions of platelets, fresh frozen plasma, and blood were given, after which the bleeding settled. Subsequent recovery was uneventful.

Discussion. Whereas some drop in platelet count is often seen after routine use of standard heparin, HIT is a more serious problem that occurs in about $3 \%$ of patients who receive the drug. ${ }^{1}$ It is characterized by thrombocytopenia, sometimes thrombosis, and the presence of an immunoglobulin $\mathrm{G}$ antibody causing complement C3-mediated platelet injury on exposure to standard heparin. Seen more often with bovine heparin than with other types, HIT typically occurs 7 to 10 days after the start of therapy. Decreasing serial platelet counts and laboratory platelet aggregation studies and serotonin release assays lead to the diagnosis. Treatment includes stopping heparin administration, giving platelet antiaggregation drugs, and, if needed, substituting other anticoagulants for heparin.

Kondo and associates ${ }^{2}$ have reviewed several options for cardiac operations in patients with HIT. These include deferring operation for a few weeks until the circulating platelet antibody levels come down; use of drugs such as aspirin, dipyridamole, and iloprost for modifying platelet activation in the presence of standard heparin; and using fibrinolytic agents and thrombin inhibitors such as ancrod, Hirudin, and Argatroban for anticoagulation. Substitution of standard heparin with heparinoids such as heparin sulphate and dermatan sulphate and LMWHs such as dalteparin (Fragmin), tedelaparin, and enoxaparin has also been reported. ${ }^{1,3}$ LMWHs are fragments cleaved from standard heparin that act mainly against clotting factor $\mathrm{Xa}$ and compared with standard heparin produce less bleeding for equivalent antithrombotic effect. Because crossreactivity with heparin is known, platelet aggregation tests are recommended to select the most appropriate $\mathrm{LMWH}{ }^{3}$ We used enoxaparin because it was readily available and with it the platelet counts in our patient remained stable.

A major drawback of use of LMWHs is the need for frequent factor $\mathrm{Xa}$ assays for accurate monitoring of anticoagulation, which necessitates a specialized setup. However, a direct correlation between activated clotting time measurements and anti-factor Xa activity has been shown, and effective anticoagulation with LMWHs can be achieved at activated clotting time values lower than those usual for CPB with standard heparin. ${ }^{4}$ Another problem with LMWHs is the inability to achieve complete reversal of anticoagulation at the end of CPB. Protamine only neutralizes their anti-IIa action, and the anti-Xa activity persists for longer. This may have partly contributed to the increased chest tube drainage in our patient.

A thromboresistant heparin-bonded perfusion circuit with its ability to eliminate the need for systemic heparinization during $\mathrm{CPB}^{5}$ is an attractive option in cases of HIT. Of particular advantage with this is a circuit with covalently bonded endpoint-attached heparin (Carmeda) that prevents leaching of any heparin into blood. An added benefit of this circuit in patients with HIT could be the decreased complement activation (C3a and C5a) and hence less contribution to the cause of HIT. However, a major limitation of these circuits is that the anticoagulant effect is flow dependent and clotting may be induced at low or stagnant flow rates and additional anticoagulation may be required for safety. We combined the Carmeda circuit with enoxaparin and obtained satisfactory anticoagulation even at low activated clotting time levels.

Thus in patients with HIT, cardiac operations can be safely done with use of a Carmeda circuit with an appropriate LMWH such as enoxaparin, although further experience is needed to establish protocols for monitoring, dosing, and neutralization of LMWHs.

\section{REFERENCES}

1. Wilhelm MJ, Schmid C, Kececioglu D, Mollhoff T, Ostermann $\mathrm{H}$, Scheld $\mathrm{HH}$. Cardiopulmonary bypass in patients with heparin-induced thrombocytopenia using Org 10172. Ann Thorac Surg 1996;61:920-4.

2. Kondo NI, Maddi R, Ewenstein BM, Goldhaber SZ. Antico- 
agulation and hemostasis in cardiac surgical patients. J Card Surg 1994;9:443-61.

3. Altés A, Martino R, Gari M, et al. Heparin induced thrombocytopenia and heart operation: management with tedelparin. Ann Thorac Surg 1995;59:508-9.

4. Koza ML, Messmore HL, Wallock ME, Walenga JM, Pifarre
ME. Evaluation of a low molecular weight heparin as an anticoagulant in a model of cardiopulmonary bypass surgery. Thromb Res 1993;70:67-76.

5. Jones DR, Hill RC, Vasilakis A, et al. Safe use of heparincoated bypass circuits incorporating a pump-oxygenator. Ann Thorac Surg 1994;57:815-9.

\title{
REOPERATION FOR ANEURYSMAL DISEASE OF THE ASCENDING AORTA IN PATIENTS WITH CONCOMITANT AORTIC VALVE INCOMPETENCE
}

\author{
Matthias Karck, MD, ${ }^{\mathrm{a}}$ Joachim Cremer, MD, ${ }^{\mathrm{a}}$ ürgen Wawersik, MD, ${ }^{\mathrm{b}}$ and Axel Haverich, MD, ${ }^{\mathrm{a}}$ Kiel, Germany
}

An incompetent aortic valve in the presence of recurrent pathologic processes of the ascending aorta poses challenges during surgical reentry of the mediastinum. This is particularly true of patients who have undergone previous cardiac or aortic operations in which the pericardium was left open with an ascending aortic aneurysm encroaching on the sternum. Our experience with seven consecutive successful reoperations on patients with such combined lesions is described.

The patient cohort consisted of seven consecutive patients operated on between October 1993 and February 1995. In all patients except one, the femoral artery and vein were exposed by groin incision. In two patients the sternum was reopened with an oscillating saw without the previous institution of femoro-femoral bypass. Retrosternal adhesions were then carefully dissected to make feasible the institution of cardiopulmonary bypass by means of ascending aortic and right atrial cannulation. In five patients, cardiopulmonary bypass was commenced through groin cannulation and the systemic temperature was lowered slightly. In two instances, complete median resternotomy was then performed with an oscillating saw. In both of these cases, subsequent dissection of retrosternal adhesions was possible without major bleeding. The aorta was then mobilized to enable aortic crossclamping. After aortotomy, the procedures were completed according to standard techniques.

In a subgroup of three patients, however, only the lower third of the sternal bone was reopened during femorofemoral cardiopulmonary bypass. With the sternal edges kept carefully elevated, the diaphragmatic aspects of the left and right ventricle were dissected first, and all retrosternal adhesions were left untouched. Then both the lateral wall of the left ventricle and the apex were exposed

From the Departments of Cardiovascular Surgery and Department of Anaesthesiology, University of Kiel, Kiel, Germany.

Received for publication Nov. 13, 1995; accepted for publication Feb. 15, 1996.

J Thorac Cardiovasc Surg 1996;112:1392-3

Copyright (c) 1996 by Mosby-Year Book, Inc.

$0022-5223 / 96 \$ 5.00+0 \quad \mathbf{1 2 / 5 4 / 7 2 8 9 5}$ to such an extent that the apex could be punctured for placement of a vent catheter. In the event of ventricular fibrillation, the heart was decompressed manually to avoid ventricular overdistention, which could well occur despite left ventricular venting. Core cooling was continued to achieve a rectal temperature of $25^{\circ} \mathrm{C}$ before induction of circulatory arrest. The systemic blood was drained, leading to partial collapse of both the heart and the ascending aorta.

Resternotomy and dissection of the remaining retrosternal adhesions were completed, safely and without damage to the adjacent right ventricle, pulmonary artery, or ascending aorta. The aorta was then mobilized as far downstream as was possible without compromising the brachiocephalic trunk. At this point, an aortic occluding clamp was gently applied and cardiopulmonary bypass was reinstituted. The time required to complete dissection of retrosternal adhesions during circulatory arrest was less than 12 minutes in all cases. In this subgroup of three patients, the body of the aneurysm was then incised anteriorly and longitudinally. In one patient, ascending aortic pathologic processes, including a chronic type A dissection with rupture of the false channel into the pleural space and additional paravalvular leakage of the previously implanted mechanical aortic valve, were seen. The other two patients had typical intimal tears in the ascending aorta as a result of acute type $\mathrm{A}$ aortic dissection, with a significant paravalvular leakage of the aortic valve prosthesis in one case. The aortic valve prosthesis in the other patient appeared competent, but it had to be replaced because massive enlargement of the sinus of Valsalva precluded secure anchoring of an ascending aortic graft except as a composite graft. In all three patients of this subgroup, composite graft replacement of the aortic valve and ascending aorta was initially performed. Meanwhile, the systemic temperature was further lowered to $20^{\circ} \mathrm{C}$. At this rectal temperature, a second period of circulatory arrest was induced to enable exploration of the aortic arch and subsequent distal reconstruction if necessary. After implantation of the distal aortic anastomosis, cardiopulmonary bypass was reinstituted. During rewarming, the graft-to-graft anastomosis was 